\title{
Impact of Student Mindfulness Facets on Engineering Education Outcomes: An Initial Exploration
}

\section{Dr. Tomas Estrada, Elizabethtown College}

Dr. Tomas Estrada is an Associate Professor in the Department of Engineering and Physics at Elizabethtown College, in Elizabethtown, PA. He received his B.S. in Electrical Engineering from Universidad de Costa Rica in 2002 and his M.S. and Ph.D. (both in Electrical Engineering) from the University of Notre Dame in 2005 and 2009, respectively. His research interests include control systems, engineering education, technology-related entrepreneurship, and sustainable engineering applications.

\section{Dr. Elizabeth D. Dalton, Elizabethtown College}

Assistant Professor of Psychology, Elizabethtown College 


\title{
Impact of Student Mindfulness Facets on Engineering Education Outcomes: An Initial Exploration
}

\begin{abstract}
Mindfulness-based practices and interventions are increasingly recognized for their potential to positively affect college students' psychological health, wellbeing, and academic success. While research on mindfulness in the context of engineering education is beginning to emerge, many concepts remain poorly understood, including the association between engineering students' mindfulness and academic functioning. Additionally, prior research has not specifically considered and tested interventions designed to increase the trait mindfulness of engineering students. In this paper, we examine these questions through two studies: the first, a survey study examining the association between trait mindfulness and relevant educational outcomes in 73 engineering and non-engineering students; the second, a pilot four-week mindfulness-based stress reduction intervention for 21 engineering students.

Results indicated that engineering students' grades on a targeted task relevant to ABET outcomes were significantly, positively related to their self-reported preference for challenging information and experiences $(\mathrm{r}=.41, \mathrm{p}<.01)$ and their ability to be mindfully nonreactive $(\mathrm{r}=$ $.38, \mathrm{p}=.01)$. Compared to non-engineering students, engineering students reported a significantly higher level of nonjudgmental mindful awareness $(t(69)=3.02, p<.01)$ and openness to new experiences $(\mathrm{t}(70)=3.42, \mathrm{p}<.01)$. Participating in a four-week mindfulness intervention significantly increased engineering students' trait mindfulness $(\mathrm{t}(21)=-2.90, \mathrm{p}=$ .01 ), engagement in mindfulness outside of sessions $(\mathrm{t}(20)=-4.36, \mathrm{p}<.01)$, and intellectual curiosity and exploration $(\mathrm{t}(21)=-.48, \mathrm{p}<.01)$. These results lend support to the feasibility of mindfulness-based interventions in engineering education and advance previous literature. The discussion provides recommendations for the implementation of mindfulness-based interventions in engineering education based on these results and qualitative student feedback, as well as recommendation for continued research in this domain.
\end{abstract}

\section{Background}

In recent years, researchers in engineering education have begun to expand beyond course- or discipline-specific studies, beginning to consider also more holistic aspects to the engineering student experience. The field has strengthened its role in enhancing the engineering student's overall experience by exploring factors such as health, wellbeing, diversity, and inclusion, as well as obstacles to student success, such as stress and anxiety. To do this effectively, it becomes necessary to look beyond the boundaries of the engineering disciplines, and to consider scholarly advances from other domains. By identifying practices and techniques shown to benefit the health and wellbeing of human beings in general, we may then investigating the role such advances may play in bolstering the experiences of engineering students. One such advance is the study of mindfulness. The impact of mindfulness in Western society has grown dramatically in recent decades, in terms of number of practitioners, teachers, and recognition in everyday 
conversations. In parallel, the Western scientific communities have begun to produce a dramatically increasing number of results and academic papers pointing to the power of mindfulness in increasing our quality of life [1]. Based on the growing body of research showing the positive effects of mindfulness, it becomes very appealing to investigate the role that mindfulness may play for our students.

While the origins of mindfulness and meditation can be traced back thousands of years to religious traditions in India and other parts of Asia, it was not until the late 20th Century that it was recognized as a legitimate field of study by Western scientific communities. Since the 1980 s, a rapidly growing number of Western scholars have begun to study and document the impact of these practices on various aspects of health and wellbeing, such as stress and pain reduction, memory, aging, happiness, etc. [2, 3]. For example, [4] summarizes many results surrounding mindfulness-based stress reduction (MBSR), and, more recently, [1] provides a comprehensive overview of studies documenting how mindfulness practices may result in permanently altered traits.

While the definitions of mindfulness may vary, the general idea is fairly consistent:

"Mindfulness means paying attention in a particular way: on purpose, in the present moment, and nonjudgmentally." [4]. Thich Nhat Hahn, a celebrated Buddhist practitioner, activist, and teacher, offers his own definition: "Mindfulness shows us what is happening in our bodies, our emotions, our minds, and in the world. Through mindfulness, we avoid harming ourselves and others." [5] Mindfulness exercises have been connected with and grounded in spiritual traditions, but largely communicated in a secular way to western audiences. Some basic examples are breathing meditation, sitting meditation, walking meditation, and yoga (movement meditation). Other areas include metta or lovingkindness meditation and compassion meditation [6].

Because of the encouraging nature of some of these experiments, an increasing number of scholars has begun to explore the role that mindfulness may play in education, both in the K-12 setting and in higher education. Regarding K-12 education, several examples are provided in [7], including recommendations on how to carry out exercises in breathing, walking meditation, and contemplation in the classroom setting. In the context of higher education, a wide variety of such examples, as well as practical recommendations from faculty across academic disciplines, are provided in [8]. For example, the authors provide examples such as walking meditation, contemplative discussion, compassion exercises, emotional wellbeing [9], lectio divina (contemplative reading) and mindful writing [10, 11].

Building on this growing body of knowledge, we seek to explore the benefits that mindfulness may play in the context of engineering education. While some studies at the intersection of these two domains have begun to appear recently, there remains much unexplored territory. Existing research has begun to explore the relationship between mindfulness and academic and psychological outcomes in engineering students. Initial questionnaire-based studies provide evidence of positive associations between engineering students' trait mindfulness (the extent to which they observe and engage with their environment and experiences in a mindful manner) and their beliefs about their abilities to be innovative, and possess relevant business-related skills $[12,13]$. Engineering students' trait mindfulness has also been demonstrated to predict improved performance on high intensity exams by lowering cognitive test anxiety [14]. These initial 
studies provide support for positive relationships between mindfulness and constructs relevant to engineering education. Less well understood is the association between engineering students' trait mindfulness and their performance on ABET-relevant educational outcomes. Additionally, as it is possible that mindfulness is associated with academic outcomes in part because it serves to promote psychological flexibility and decrease avoidance of emotions like anxiety and uncertainty, it would also be important to know and understand whether engineering students' mindfulness is associated with their intellectual curiosity and exploration [14]. Furthermore, the extent to which engineering students are similar to or different from college student populations with which there is a more established body of mindfulness literature (e.g., psychology majors, occupational therapy majors) is unknown. Study 1 will seek to address these questions by sampling engineering and non-engineering (psychology and occupational therapy) students about their trait mindfulness facets, intellectual curiosity and exploration, and grades on relevant educational assessments.

Survey studies have also garnered support for negative correlations between engineering students' mindfulness and facets of their mental health. For example, [15] found that mindfulness is inversely associated with perceived stress in Indian engineering students. A questionnaire-based study of students in psychology, engineering, and the medical sciences showed support for a relationship between mindfulness and depressive symptoms, such that lower levels of trait mindfulness were associated with less depressive symptoms [16]. It is not known, however, if learning and practicing mindfulness can actually alter the stress levels, or other indices of psychological wellbeing, of engineering studies.

Few if any studies have sought to actually effect change in engineering students' trait mindfulness using mindfulness training interventions. In [17], a study is presented in which firstyear engineering students were provided with a 45-minute informational session about contemplative practices including mindfulness. This study demonstrated that students were receptive and responded positively to a 45-minute information session, which lends further support to the idea that engineering students might be receptive and responsive to formal mindfulness-based interventions. This study did not, however, assess whether this information session affected change in engineering students' trait mindfulness [17].

Studies of mindfulness-based interventions in non-engineering college students have found that relatively brief (e.g,. four to eight week) mindfulness interventions can increase trait mindfulness, and, in some cases, elicit positive changes in mental health [18, 19, 20]. As this has not previously been examined specifically in engineering students, the present study will pilot a four-week, once-weekly mindfulness intervention for undergraduate engineering students in a small, undergraduate liberal arts school. The aims of the second study are to examine whether a four-week mindfulness intervention can effect change in engineering students' trait mindfulness, perceived stress, and intellectual curiosity and exploration. A secondary aim is to assess feasibility of such an intervention by querying students about their perceptions of the intervention, and practice of mindfulness skills provided in the intervention sessions outside of session. Taken together, these studies will advance understanding of the relationship between engineering students' trait mindfulness, academic functioning, and perceived stress, and begin to explore interventions that might enhance engineering students' trait mindfulness. 
Study 1.

\section{Purpose of Study and Primary Research Questions}

In Study 1, we seek to expand upon the emerging body of research on mindfulness in the context of engineering education by exploring the relationship between the trait mindfulness of engineering students and relevant outcomes in engineering education. We used the Five Facet Mindfulness Questionnaire (FFMQ) tool [21] to measure the former, and the outcomes from ABET, the national accreditation board for engineering programs, to inform the latter. In particular, we selected ABET Outcome 1 ("an ability to identify, formulate, and solve complex engineering problems by applying principles of engineering, science, and mathematics", [22]) as particularly relevant, and one whose relationship to mindfulness traits may not have been immediately apparent.

Our study then, seeks to address the following research question.

Research Question 1.

What relationships exist between the mindfulness facets of engineering students and their performance on relevant ABET outcomes?

Additionally, we have collected information on students from other fields as well, so as to explore the following question:

Research Question 2.

How do the mindfulness facets of engineering students compare to those of psychology and occupational therapy students?

Study 2.

In Study 2, we seek to test whether engineering students' trait mindfulness increases following participation in a mindfulness intervention. While previous research suggests that nonengineering college students respond favorably to mindfulness interventions, this premise has not been tested in engineering students specifically. The intervention is specifically informed by the mindfulness-based stress reduction approach developed by [23]. A mindfulness intervention rooted in stress reduction was selected as stress is increasingly cited as a concern and impediment to academic success and wellbeing among college students, and mindfulness interventions hold promise for helping to alleviate stress and anxiety in this population [24, 25].

Research Question 3.

-What is the effect of a 4-week mindfulness intervention on trait mindfulness and perceived stress of engineering students? 


\section{Methods}

\section{Study 1}

Participants and Procedures

Participants for the initial study included 73 undergraduate students at a small liberal arts college in the mid-Atlantic region. Study participants were recruited from ongoing classes in engineering $(\mathrm{n}=44)$ and psychology $(\mathrm{n}=16$ psychology majors, 8 occupational therapy majors, 2 social work majors, 3 assorted other majors). The study sample was predominantly white (85\%), male (55\%), and 19.6 years-old on average. Participants providing informed consent completed questionnaire packets (specific measures/surveys described in detail below), and consented for their grades in ongoing engineering classes (if relevant) to be used as part of the study. All study procedures were approved by the Institutional Review Board at Elizabethtown College.

\section{Measures}

Intellectual curiosity and exploration. Participants' intellectual curiosity and exploration was assessed using the Curiosity and Exploration Inventory (CEI-II, [26]). This is a 10-item measure designed to assess agreement on a 5 point scale with items that assess intellectual stretching, or motivation to seek out new experiences and knowledge (e.g., "I actively seek as much information as I can in new situations.") and embracing, or an openness to novel experiences and uncertainty (e.g., "I am the type of person who really enjoys the uncertainty of everyday life."). The CEI-II is a commonly employed measure of intellectual curiosity in college students and has good reliability and validity [26].

Mindfulness. Participants' mindfulness was assessed using the Five Facet Mindfulness Questionnaire (FFMQ, [21]). This is a 39-question item designed to assess agreement on a 5 point scale with 5 facets of mindfulness: observing items (e.g., "When I'm walking, I deliberately notice the sensations of my body moving."); describing items (e.g., "I'm good at finding words to describe my feelings."); acting with awareness (e.g., "When I do things, my mind does not wander off and I'm not easily distracted."); nonjudgment (e.g., "I don't make judgments about whether my thoughts are good or bad."); and nonreactivity (e.g., "I perceive my feelings and emotions without having to react to them."). The FFMQ has established reliability and validity, and has demonstrated to be sensitive to change in prior mindfulness intervention studies $[21,27]$.

ABET Outcomes. In this study we focused on ABET Outcome 1, "an ability to identify, formulate, and solve complex engineering problems by applying principles of engineering, science, and mathematics" [22]. In particular, we selected ABET Outcome 1 as it is one of the most central to engineering curricula regardless of discipline, and one whose relationship to mindfulness traits may not have been immediately apparent. The targeted task utilized to measure academic success on this aspect was the first partial exam in a Circuit Analysis course. The exam was selected as a targeted task for this outcome, as it consisted of four long, multi-step problems, requiring an understanding of how to apply both circuit laws and principles from physics and mathematics. 


\section{Study 2}

Participants and Procedures

Participants for the second study included 21 undergraduate engineering majors. The sample was predominantly white (74\%; 9\% Latino/Hispanic, 9\% biracial/multiracial; 4\% Asian, 4\% other/prefer to self-describe), male (61\%) and 22 years-old on average. Participants providing informed consent completed 4 weekly, hour-long mindfulness intervention sessions led by study co-author Dr. Elizabeth Dalton, a clinical psychologist with training in mindfulness-based interventions, as well and pre and post measures of their mindful awareness and other relevant outcomes (described below). Participants received extra credit in one of their ongoing engineering courses for their participation. All study procedures were approved by the Institutional Review Board at Elizabethtown College.

Mindfulness-Based Stress Reduction Intervention (MBSRI)

The mindfulness intervention provided was based on mindfulness-based stress reduction as developed by [23] and [28], and included 4 weekly hour-long sessions. Prior studies have demonstrated effectiveness of four weekly hour-long mindfulness sessions in general healthy volunteer samples [20,29]. Each of the four sessions included a psychoeducational component (e.g., about the nature of stress, and the purpose and attitudes of mindfulness), an experiential practice (e.g., mindful eating, walking, and breathing), opportunity for reflection and questions, and suggested at-home practices.

Baseline Measures

Baseline measures included the same assessments described above for Study 1 to assess mindfulness (FFMQ) and intellectual curiosity (CEI-II). Participants' perceived stress was also assessed using the Perceived Stress Scale (PSS, [30]), in order to both quantify students' baseline levels of stress, and examine the effects of the MBSRI intervention on students' stress levels. This is a widely-used measure of general perceived stress with well-established reliability and validity [31]. Students consented for their grades in ongoing engineering courses to be used as indicators of academic success based on ABET outcomes.

\section{Follow-Up Measures}

Follow-up measures included measures of mindfulness (FFMQ), intellectual curiosity (CEI-II), and stress (PSS). Additionally, participants responded to open-ended and closed-ended questions about their experience in and utility of the mindfulness group, including the frequency with which they did or did not complete at-home mindfulness practices. Participants also provided information about any barriers to mindfulness practice encountered (both the formal groups and at-home practices).

Data Analysis

Data analysis was conducted using IBM Statistics Software Version 24 [32]. Primary statistical analysis included Pearson's $r$ correlations to assess relationships amongst study variables, 
independent samples t-tests for comparison of engineering and non-engineering students, and paired-samples t-tests to examine within-subject changes pre and post intervention.

\section{Results}

Study 1. Relationship Between Mindfulness, Academic Performance, and Intellectual Curiosity

Engineering students' grades on the selected ABET-relevant assignment were significantly, positively related to their self-reported intellectual stretching (or preference for challenging information) and their ability to be mindfully nonreactive, but not other facets of mindfulness (see Table 1 for descriptive statistics and correlations). Students' intellectual stretching was also significantly related to their mindful observation and nonreactivity, while intellectual embracing was positively related to nonreactivity (see Table 1).

Study 1. Comparison of Engineering Students and Non-Engineering Students

Compared to non-engineering students, engineering students reported a significantly higher level of nonjudgmental mindful awareness $(\mathrm{t}(69)=3.02, \mathrm{p}<.01)$ and openness to new experiences $(\mathrm{t}$ $(70)=3.42, p<.01)$, and trended towards a higher level of nonreactivity $(\mathrm{t}(70)=1.84, \mathrm{p}=.07)$, but did not differ significantly in other facets of mindfulness or openness to new experiences. The observed differences between engineering and non-engineering students may have been attributable in part to gender, as the engineering students were $80 \%$ male and the nonengineering students (primarily psychology and occupational therapy students) were $83 \%$ female. Comparisons by gender produced a similar pattern of results to those above, with male students reporting higher degrees of mindful non-reactivity and preferences for challenging information compared to female students. 
Table 1. Descriptive statistics and correlations amongst primary study variables for Study 1.

\begin{tabular}{|c|c|c|c|c|c|c|c|c|c|c|c|}
\hline Variable & Average & $\begin{array}{l}\text { Standard } \\
\text { Deviation }\end{array}$ & $\begin{array}{l}\text { Observed } \\
\text { Range }\end{array}$ & 1 & 2 & 3 & 4 & 5 & 6 & 7 & 8 \\
\hline 1. Grade & 80.13 & 12.31 & $48-100$ & & $.40 * *$ & .01 & .15 & .12 & -.11 & -.11 & $.38 * *$ \\
\hline $\begin{array}{l}\text { 2. Intellectual } \\
\text { Stretching }\end{array}$ & 14.15 & 2.51 & $8-20$ & $.40 * *$ & & $.40 * *$ & $.36^{* *}$ & .04 & .16 & .05 & $.44 * *$ \\
\hline $\begin{array}{l}\text { 3. Intellectual } \\
\text { Embracing }\end{array}$ & 15.63 & 4.30 & $7-25$ & .01 & $.40 * *$ & & .14 & -.15 & -.07 & .16 & $.29 *$ \\
\hline $\begin{array}{l}\text { 4. Mindful } \\
\text { Observing }\end{array}$ & 3.24 & 0.68 & $1.75-4.75$ & .15 & $.36^{* *}$ & .14 & & .21 & .15 & -.02 & $.28^{*}$ \\
\hline $\begin{array}{l}\text { 5. Mindful } \\
\text { Describing }\end{array}$ & 3.12 & 0.84 & $1.63-4.88$ & .12 & .04 & -.15 & .21 & & $.43 * *$ & $.27 *$ & .13 \\
\hline $\begin{array}{l}\text { 6. Acting w/ } \\
\text { Awareness }\end{array}$ & 3.06 & 0.67 & $1.50-4.75$ & -.11 & .16 & -.07 & .15 & $.43 * *$ & & $.34 * *$ & .17 \\
\hline 7.Nonjudgment & 2.99 & 0.89 & $1.13-4.75$ & -.11 & .05 & .16 & -.02 & $.27 *$ & $.34 * *$ & & .21 \\
\hline 8.Nonreactivity & 3.02 & 0.68 & $1.00-4.43$ & $.38 *$ & $.33 * *$ & $.29 *$ & $.28 *$ & .13 & .17 & .21 & \\
\hline
\end{tabular}

Figure 1. Baseline Associations Between Perceived Stress and

Mindful Nonjudgment, Nonreactivity

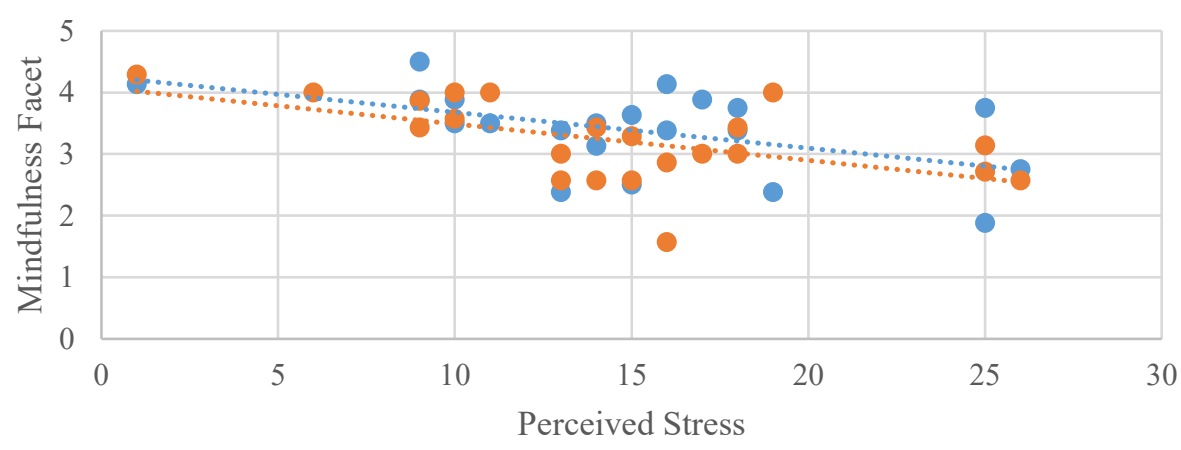

- Mindful Nonjudgment Mindful Nonreactivity

- Linear (Mindful Nonjudgment) ........ Linear (Mindful Nonreactivity) 
Study 2. Effects of Mindfulness Intervention

Students' overall trait mindfulness was significantly higher immediately after the four-week intervention $(\mathrm{M}=130.86, \mathrm{SD}=19.57)$ than it was prior to the intervention $(\mathrm{M}=126.38, \mathrm{SD}=$ 16.48); $\mathrm{t}(21)=-2.90, \mathrm{p}=.01$, Cohen's d effect size $=0.65$ (medium). Two specific mindfulness traits increased post-intervention: mindful observation (pre intervention $\mathrm{M}=3.09, \mathrm{SD}=0.48$; post intervention $\mathrm{M}=3.2, \mathrm{SD}=.51 ; \mathrm{t}(20)=-3.42, \mathrm{p}<.01$; Cohen's $\mathrm{d}=0.73$, medium) and mindful description (pre-intervention $\mathrm{M}=3.08, \mathrm{SD}=0.70$; post-intervention $\mathrm{M}=3.32, \mathrm{SD}=$ 0.87 ; $\mathrm{t}(20)=-2.88, \mathrm{p}<.01$; Cohen's $\mathrm{d}=0.65$, medium). The other specific mindfulness traits acting with awareness, nonjudgment, and nonreactivity - did not change significantly following the intervention. Students' intellectual stretching was also significantly higher after the intervention $(\mathrm{M}=16.29, \mathrm{SD}=2.24)$ than it was prior to the intervention $(\mathrm{M}=14.81, \mathrm{SD}=2.20)$; $\mathrm{t}(21)=-.48, \mathrm{p}<.01$, Cohen's d effect size $=1.05$ (large). There were no significant changes to students' perceived stress $(\mathrm{t}(19)=.33, \mathrm{p}=.74)$ or intellectual embracing $(\mathrm{t}(20)=-1.88, \mathrm{p}=$ $.08)$.

Study 2. Feasibility of the Mindfulness Intervention

On average, students attended 3.5 out of 4 of the weekly hour-long mindfulness sessions. Students' weekly practices (outside of the intervention sessions) improved significantly from before the intervention $(\mathrm{M}=0.45, \mathrm{SD}=1.20)$ to after the intervention $(\mathrm{M}=3.74, \mathrm{SD}=3.85)$; $\mathrm{t}(20)=-4.36, \mathrm{p}<.01$; Cohen's d effect size $=0.95$ (large). With regards to preferences for session length, $86 \%$ of participants reported that they would prefer to keep the session length the same, $9 \%$ reported they would have preferred shorter sessions, and 5\% reported they would have preferred longer sessions. With regards to preferences for frequency of session meeting, $82 \%$ reported they would prefer to keep the weekly session schedule, while $18 \%$ reported they would have preferred to meet more frequently throughout the week. On a 7-point likert scale, the students' average rating of the helpfulness of sessions was 6/7 (corresponding with "pretty helpful," 7 was highest rating). On a 5 point scale of anticipated frequency of application of the scales, students' average rating was a 3.31 out of 5 (corresponding with "will use occasionally").

Students also provided qualitative written feedback. When prompted to identify barriers that arose to practicing mindfulness outside of sessions, students' identified the following: "forgot/didn't think about it;" "rushing;" "lack of focus;" and "distraction." In an open ended question prompting students to identify elements of the intervention they liked and would retain, some of the most common answers were: "practicing specific techniques" (6), "range/variety of activities practiced" (5), and "being seated in a circle" (2). In an open ended question prompting students to identify elements of the intervention they disliked or would change, answers included: "more space in the meeting room" (2) and "more mindful activities involving movement" (2); no other answers were duplicated. 
Table 2. Descriptive statistics and correlations among primary study variables at study follow-up.

\begin{tabular}{|c|c|c|c|c|c|c|c|c|c|c|c|c|c|}
\hline Variable & Average & $\begin{array}{l}\text { Standard } \\
\text { Deviation }\end{array}$ & $\begin{array}{l}\text { Observed } \\
\text { Range }\end{array}$ & 1 & 2 & 3 & 4 & 5 & 6 & 7 & 8 & 9 & 10 \\
\hline 1. GPA & 3.54 & 0.39 & $2.70-3.98$ & & .01 & .09 & $-.40 \dagger$ & .28 & .32 & .01 & .17 & .31 & .37 \\
\hline $\begin{array}{l}\text { 2. Intellectual } \\
\text { Stretching }\end{array}$ & 16.32 & 2.19 & $12-20$ & .01 & & .26 & $-.51 *$ & $.62 * *$ & .28 & $.63^{* *}$ & $.46^{*}$ & .25 & $.55^{* *}$ \\
\hline $\begin{array}{l}\text { 3. Intellectual } \\
\text { Embracing }\end{array}$ & 16.22 & 5.95 & $9-35$ & .09 & .26 & & .00 & .19 & .36 & .25 & .06 & -.07 & .20 \\
\hline $\begin{array}{l}\text { 4. Perceived } \\
\text { Stress }\end{array}$ & 14 & 6.29 & $1-30$ & $-.40 \dagger$ & $-.51 *$ & .00 & & $-72 * *$ & -.17 & $-.46^{*}$ & $-.53 *$ & $-.68 * *$ & $-.68 * *$ \\
\hline $\begin{array}{l}\text { 5. FFMQ } \\
\text { Total Trait } \\
\text { Mindfulness }\end{array}$ & 130.78 & 19.10 & $83-158$ & .28 & $.62 * *$ & .19 & $.72 * *$ & & $.57 * *$ & $.81 * *$ & $.87 * *$ & $.63 * *$ & $.57 * *$ \\
\hline $\begin{array}{l}\text { 6. Mindful } \\
\text { Observing }\end{array}$ & 3.42 & 0.50 & $2.13-4.50$ & .32 & .28 & .36 & -.17 & $.57 * *$ & & .29 & $.53^{*}$ & .07 & $.39 \dagger$ \\
\hline $\begin{array}{l}\text { 7. Mindful } \\
\text { Describing }\end{array}$ & 3.31 & 0.85 & $1.38-4.75$ & .01 & $.63^{* *}$ & .25 & $-.46^{*}$ & $.81 * *$ & .29 & & $.60 * *$ & $.48^{*}$ & .21 \\
\hline $\begin{array}{l}\text { 8. Acting w/ } \\
\text { Awareness }\end{array}$ & 3.20 & 0.77 & $1.38-4.88$ & .17 & $.46^{*}$ & .06 & $-.53 *$ & $.87 * *$ & $.53 *$ & $.60^{*}$ & & .35 & $.51 *$ \\
\hline $\begin{array}{l}9 . \\
\text { Nonjudgment }\end{array}$ & 3.48 & 0.83 & $1.13-5.00$ & .31 & .25 & -.07 & $\begin{array}{l}- \\
.68 * *\end{array}$ & $.63^{* *}$ & .07 & $.48^{*}$ & .35 & & .15 \\
\hline $\begin{array}{l}10 . \\
\text { Nonreactivity }\end{array}$ & 3.37 & 0.61 & $2.14-4.29$ & .37 & $.55^{* *}$ & .20 & $-70 * *$ & $.57 * *$ & $.39 \dagger$ & .21 & $.51 *$ & .15 & \\
\hline
\end{tabular}

\section{Discussion}

The present work sought to expand upon prior research on the role of mindfulness in engineering education. The first study examined the relationship between specific facets of mindfulness and students' intellectual curiosity and academic performance, and compared the self-reported mindfulness of engineering students to students of other majors. Results from Study 1 revealed that specific facets of mindfulness were not equal in their association with academic outcomes. Rather, among engineering students, mindful nonreactivity emerged as the facet of mindfulness with the most robust and consistent associations with academic outcomes. Mindful nonreactivity was significantly, positively correlated with engineering students' grades on ABET-relevant course assignments, as well as self-rated intellectual curiosity and exploration.

In the mindfulness literature, nonreactivity is conceptualized as the ability to refrain from responding to thoughts, emotions, or other stimuli in a reactive manner [33]. Prior research has found that mindful nonreactivity is negatively associated with dysphoric mood states and positively associated with acceptance and reappraisal, or the ability to cognitively reframe 
perceptions of or reactions to events $[34,35]$. It has been suggested that nonreactivity facilitates the ability of mindful observation of one's thoughts and feelings to contribute to wellbeing, rather than contributing to negative affective states or rumination [36]. Indeed, prior research has indicated that mindful nonreactivity promotes reduced experiences of negative affect (e.g., anxiety, sadness) by facilitating individuals' ability to reappraise, or think differently about, their experiences [33]. It is plausible, then, that the ability to observe and experience academic-related experiences (e.g., introduction to new, challenging material, examinations and presentations) nonreactively (e.g., without dwelling on or reacting to negative thoughts or emotions that these experiences may trigger) could facilitate adaptive responding, and subsequent success. Importantly, it was also noted that mindful nonreactivity was associated with intellectual stretching and embracing in the present sample, indicating that students who respond to situations nonreactively are also more likely to seek out novel information and take academic risks. It is plausible that such tendencies would facilitate success in the engineering field.

Interestingly, where engineering students differed from non-engineering students (predominantly psychology and occupational therapy students) in their self-rated mindfulness, engineering students showed relatively higher levels of mindfulness. These findings are promising in that they suggest an opportunity to highlight, tap into, and enhance engineering students' existing mindful capabilities. Students may or may not be aware of the ways in which deliberately cultivating and enhancing mindful awareness and responses can improve academic and psychological wellbeing.

The second study provides preliminary evidence in support of the feasibility and effectiveness of relatively brief ( 4 week) intervention to enhance the trait mindfulness of engineering students. Engineering students' overall trait mindfulness was significantly higher upon conclusion of the four week intervention and, importantly, students reported that they were using and practicing mindfulness outside of the intervention sessions. Specifically, students reported that before the intervention they practiced mindfulness 0.4 times per week on average, which increased to 3.7 times per week on average upon conclusion of the intervention. While prior research has not tested effects of mindfulness-based interventions on engineering students' trait mindfulness, these results are consistent with outcomes of mindfulness studies in other samples. For example, four week mindfulness interventions have been shown to significantly improve the trait mindfulness of college student binge drinkers [19].

The specific facets of mindfulness that increased following intervention were mindful observation and description. The fact that mindful observation and description, specifically, were seen to increase following the intervention is consistent with previous literature examining mindfulness for non-engineering college students. In a study of first-year medical and psychology students, students were able to grasp the attentional components of mindfulness as instructed in an intervention, but less so more complex attitudinal facets of mindful awareness such as radical acceptance and non-striving [37]. In the present study, mindful description and observation were a key component of each mindful practice reviewed and practiced during the intervention sessions; thus, it makes sense that they were seen to increase. The other facets of mindfulness - nonjudgment, nonreactivity, and acting with mindful awareness - are slightly more complex attitudinal facets of mindfulness that, while addressed in the intervention group, may take longer to cultivate. Students' intellectual stretching, or motivation to seek out new 
experiences and information, was also significantly higher after the intervention than it was before. Given that mindfulness practices encouraged an open and nonjudgmental attitude towards all experiences, it is plausible that increasing mindful awareness increases one's willingness to engage in and experience new intellectual stimuli.

The present study demonstrated support not only for an effect of the mindfulness intervention on students' trait mindfulness, but also for the feasibility of such an intervention. While students were likely incentivized in some part by receiving a small amount of extra credit towards an ongoing engineering course, their participation was nonetheless entirely voluntary and took place outside of course hours (specifically, from 4:00-5:00 PM on Wednesday or Thursday afternoons). Results indicated that vast majority (82-86\%) of participants felt that the session length and meeting frequency was appropriate; $18 \%$ noted that they would have preferred to meet more frequently. This suggests that engineering students are willing to engage in mindfulness practice outside of course hours. In qualitative feedback, students commented that they appreciated learning a wide range and array of both "formal" (i.e., guided, such as meditative reflection on the breath) and "informal" (i.e., mindful engagement in an everyday activity such as eating or walking) mindfulness practices. The range of activities included in the present intervention included guided breathing meditations, body scans, loving-kindness meditations, and mindful reading, drawing, eating, and walking. In identifying barriers to practicing mindfulness outside of sessions, students most frequently identified forgetting to practice. Future mindfulness-based interventions for engineering students might consider between-session reminders (e.g., via email or text), perhaps with prompts for specific practices, to help address this barrier.

Notably, several limitations of the current study should be kept in mind when interpreting the results. Most importantly, while the present study significantly advances prior research on engineering in mindfulness education by testing an intervention to enhance students' mindfulness, implications are limited by the small sample size $(\mathrm{n}=21)$ and lack of study control group. Future studies should include random assignment of engineering students to completion of a four week mindfulness intervention vs. control condition (e.g., waitlist, or psychoeducation on stress), in order to be able to conclude that it was the intervention itself, and not some other variable, that contributed to increased mindfulness in study participants. While it seems unlikely that students' trait mindfulness would spontaneously increase over the course of a semester, and hence likelier that it was the intervention itself that contributed to the observed increase in trait mindfulness following the intervention, a randomized controlled trial is nonetheless needed in order to bolster this conclusion.

Additionally, the effects of mindfulness interventions on engineering students' psychological wellbeing continues to merit investigation. In the current study, students' perceived stress levels did not change significantly over the course of the intervention. While this may be because enhancing mindfulness does not combat stress in engineering students, or because the four-week intervention was not sufficient to produce changes to psychological stress, this cannot be concluded definitively, due in part to the lack of control group. Importantly, results of Study 2 demonstrated a significant, negative correlation between engineering students' perceived stress and trait mindfulness, such that higher trait mindfulness was associated with lower perceived 
stress at both study baseline and conclusion. This indicates that there is a relationship between perceived stress and mindfulness in engineering students, even if stress levels did not change in the current investigation. It is possible that engineering students' perceived stress generally increases over the course of a semester, as assignment and exam load begins to increase, and that participation in a mindfulness intervention counteracted some of these effects. However, this cannot be definitely determined on the basis of the present investigation.

As the impact and benefits of mindfulness continue to be progressively better understood by researchers in diverse fields, we believe it particularly relevant for the engineering education community to investigate the role that mindfulness may have in enhancing the experience of our students. To this end, the present paper makes significant contributions to the existing body of

research, furthering our understanding of the connections between mindfulness and engineering education. Through our first study, we have investigated which specific facets of mindfulness correlate with performance in targeted tasks relating to ABET Outcome 1 (identifying and solving engineering problems). In future work, it is appealing to investigate which correlations may exist between facets of mindfulness with other ABET outcomes, such as the ability to function effectively on a team and to communicate effectively with a wide range of audiences. Through our second study, we have provided strong evidence indicating that mindfulness-based stress reduction, and mindfulness-based interventions more broadly, hold promise in the context of engineering education. To the authors' knowledge, no previous study has investigated a brief, multi-week intervention for engineering students specifically. The present results are, broadly speaking, consistent with research on the utility of mindfulness interventions for college students more broadly. We invite other researchers to expand upon this work by investigating the role of other types of interventions, possibly with larger groups, longer periods of time, or targeting specific mindfulness traits. It is our hope that, through the ongoing work of the engineering education community, just as society as a whole benefits from the increased role of mindfulness, our engineering students too may benefit from an increased understanding of the role of mindfulness in their educational experience.

\section{References}

[1] Goleman, Daniel and Davidson, Richard (2017). Altered Traits. New York: Penguin Random House.

[2] Siegel, D.J. (2007). The mindful brain: Reflection and attunement to the cultivation of wellbeing. New York, NY: Norton.

[3] Ricard, M. (2003). Happiness: a guide to developing life's most important skill. New York, NY: Little, Brown. 
[4] Kabat-Zinn, Jon (2013). Full Catastrophe Living: Using the Wisdom of Your Body and Mind to Face Stress, Pain, and Illness. New York: Bantam Books.

[5] Hahn, T.N. (1991) Peace is every step: the path of mindfulnes in everyday life. New York, NY: Bantaom Books.

[6] Salzberg, S. (1995). Lovingkindness: The revolutionary art of happiness. Boston: Shambhala.

[7] Rechtshaffen, D. (2014) The way of mindful education. New York, NY: Norton.

[8] Barbezat, D. and Bush, M. (2014). Contemplative Practices in Higher Education: Powerful Methods to Transform Teaching and Learning. San Francisco, CA: Josey-Bass.

[9] Axelrod, R. (1988). The evolution of cooperation. In A. Gromyko and M. Hellman (eds/), Breakthrough: Emerging new thinking: Soviet and Western scholars issue a challenge to build a world beyond war (pp.185-192). New York, NY: Walker \& Company.

[10] Ginsberg, A. (2001). Deliberate prose: selected essays, 1952-1955. New York, NY: Harper Perennial.

[11] Mitchell, S. (1990). Parables and portraits, New York, NY: Harper.

[12] Rieken, B., \& Schar, M., \& Shapiro, S., \& Gilmartin, S. K., \& Sheppard, S. (2017,a), Exploring the Relationship between Mindfulness and Innovation in Engineering Students, ASEE Annual Conference \& Exposition, Columbus, $\mathrm{OH}$.

[13] Rieken, B. (2017,b). "Trait Mindfulness in an Engineering Classroom: An Exploration of the Relationship between Mindfulness, Academic Skills, and Professional Skills.” Frontiers in Education, October 12-15, Erie, PA.

[14] Bellinger, D. B., DeCaro, M. S., \& Ralston, P. S. (2015). Mindfulness, anxiety, and highstakes mathematics performance in the laboratory and classroom. Consciousness And Cognition: An International Journal, 37123-132. doi:10.1016/j.concog.2015.09.001

[15] Vinothkumar, M., Vinu, V., \& Anshya, R. Mindfulness, hardiness, perceived stress among engineering and BDS students. Indian Journal of Positive Psychology, 4(4), 514-517.

[16] Svendsen, J. L., Kvernenes, K. V., Wiker, A. S., \& Dundas, I. (2016). Mechanisms of mindfulness: Rumination and self-compassion. Nordic Psychology, 14, 39.

[17] Huerta, M. (2018). Inner Engineering: A Convergent Mixed Methods Study Evaluating the Use of Contemplative Practices to Promote Resilience Among Freshman Engineering Students. ASEE Annual Conference and Exposition. 
[18] Gu, Y., Xu, G., Zhu, Y. (2018). A randomized controlled trial of mindfulness-based cognitive therapy for college students with ADHD. Journal of Attention Disorders, 22(4), 388399.

[19] Mermelstein, L. C., \& Garske, J. P. (2015). A brief mindfulness intervention for college student binge drinkers: A pilot study. Psychology of Addictive Behaviors, 29(2); 259-269.

[20] Shearer, A., Hunt., M., Chowdhury, M., \& Nicol, L. (2016). Effects of a Brief Mindfulness Meditation Intervention on Student Stress and Heart Rate Variability. International Journal of Stress Management, 23(2); 232-254.

[21] Baer, R. A., Smith, G. T., Hopkins, J., Krietemeyer, J., \& Toney, L. (2006). Using selfreport assessment methods to explore facets of mindfulness. Assessment, 13, 27-45.

[22] ABET website (2018): www.abet.org

[23] Kabat-Zinn, J. (2003). Mindfulness-based stress reduction (MBSR). Constructivism in the Human Sciences, 8(2), 73-107.

[24] Bamber, M. D., Schneider, J. K. (2016). Mindfulness-based meditation to decrease stress and anxiety in college students: A narrative synthesis of the research. Educational Research Review, 18, 1-32.

[25] Reiter, B., Nash, R., McCrady, M., Rhoades, D., Linscomb, M., Clarahan, M., \& Sammut, S. (2015). The prevalence and correlates of depression, anxiety, and stress in a sample of college students. Journal of Affective Disorders, 173(1), 90-96.

[26] Kashdan, T. B., Gallagher, M. W., Silvia, P. J., Winterstein, B. P., Breen, W. E., Terhar, D., \& Steger, M. F. (2009). The Curiosity and Exploration Inventory-II. Development, factor structure, and psychometrics. Journal of Research in Personality, 43, 987-998.

[27] Goldberg, S. B., Wielgosz, J., Dahl, C., Schuyler, B., MacCoon, D. S., Rosenkranz, M., Lutz, A., Sebranek, C. A., ... Davidson, R. J. (2015). Does the Five Facet Mindfulness Questionnaire measure what we think it does? Construct validity evidence from an active controlled randomized clinical trial. Psychological Assessment, 28(8), 1009-14.

[28] Stahl, B., \& Goldstein, E. (2010). A Mindfulness-Based Stress Reduction Workbook. Oakland, CA: New Harbinger Publications.

[29] Stew, G. (2011). Mindfulness training for occupational therapy students. British Journal of Occupational Therapy, 74(6), 269-276.

[30] Cohen, S., Kamarck, T., and Mermelstein, R. (1983). A global measure of perceived stress. Journal of Health and Social Behavior, 24, 386-396. 
[31] Cohen, S. and Williamson, G. Perceived Stress in a Probability Sample of the United States. Spacapan, S. and Oskamp, S. (Eds.) The Social Psychology of Health. Newbury Park, CA: Sage, 1988.

[32] IBM Corp. Released 2016. IBM SPSS Statistics for Windows, Version 24.0. Armonk, NY: IBM Corp.

[33] Curtiss, J., Klemanski, D. H., Andrews, L. Ito, M., \& Hofmann, S. G. (2017). The Conditional Process Model of Mindfulness and Emotion Regulation: An Empirical Test. Journal of Affective Disorders, 212, 93-100.

[34] Ciesla, J. A., Reilly, L. C., Dickson, K. S., Emanuel, A. S., \& Updegraff, J. A. (2012). Dispositional Mindfulness Moderates the Effects of Stress Among Adolescents: Rumination as a Moderator. Journal of Clinical Child \& Adolescent Psychology, 41(6), 760-770.

[35] Luca, I., Lauriola, M., Chiesa, V., \& Cafaro, F. (2017). Dimensions of Mindfulness and Their Relations with Psychological Well-Being and Neuroticism, Mindfulness, 8(3), pp 664-676.

[36] Desrosiers, A., Vine, V., Curtiss, J., Klemanski, D. H. (2014). Observing nonreactively: A conditional process model linking mindfulness facets, cognitive emotion regulation strategies, and depression and anxiety symptoms. Journal of Affective Disorders, 165, 31-37.

[37] Solhaug, I., Eriksen, T. E., de Vibe, M., Haavind, H., Friborg, O., Sørlie, T., \& Rosenvinge, J. H. (2016). Medical and psychology student's experiences in learning mindfulness: Benefits, paradoxes, and pitfalls. Mindfulness, 7(4), 838-850. doi:10.1007/s12671-016-0521-0 